\section{College Chemistry}

An Introductory Textbook of General Chemistry. By Prof. Linus Pauling. Third edition. Pp. xxiv +832 . (San Franciseo and London: W. H. Freeman and Company, 1964.) 50s.

$7 \mathrm{HE}$ third edition of College Chemistry brings in a wider range of topics, including a final chapter on the thirty-four fundamental particles. The theory is gradually and clearly introduced and includes some more advanced topics, such as Boltzmann's theorem from both the classical and quantum aspects. The sections on molecular structure, based on the valence bond and resonance theories, are clear and provide numerical data and graphs which add to their usefulness. The theory of metals and alloys is dealt with. Statistical mechanics rather than thermodynamics is mainly emphasized, but free energy and entropy are used in connexion with equilibrium; otherwise enthalpy changes are given prominence. The descriptive chemistry, including some organic chemistry, is adequately presented for a book of this character, and some attention is given to the history of chemistry. In discussing the elements and compounds, emphasis is laid on systematization, but sufficient detail is given to make the information worth while. The reaction for the preparation of chlorine dioxide given on p. 371 is incorrect. On p. 377 iodine dioxide is said to be paramagnetic and hence to have the formula $\mathrm{IO}_{2}$ and not $\mathrm{I}_{2} \mathrm{O}_{4} ;$ it is in fact diamagnetic and the formula cannot be $\mathrm{IO}_{2}$. There is a good description of the transuranium elements and related subjects. There is no doubt that this book, which has been carefully planned and written, will continue to enjoy the popularity which it fully deserves.

J. R. Partington

\section{Order-Disorder Phenomena}

By H. S. Green and C. A. Hurst. (Monographs in Statistical Physics and Thermodynamics, Vol. 5.) Pp. $x+363$. (London and New York: Interscience Publishers, a Division of John Wiley and Sons, Inc., 1964.) $105 s$.

$O_{R D E}$-Disorder Phenomena is Volume 5 in a serios of monographs edited by Prof. Progogine. So far, this series has produced one volume which is a very advanced text-book and four learned monographs. One may ask at this stage whether the series roally provides scientists and engineers with "a comprehensivo treatment of the basic methods of statistical mechanics" as is claimed. I seriously doubt whether this aim has been realized, and the relatively excessive price of the volumes in the series indicatos also a lack of conviction on the part of the publishers.

If, however, one considers this series to be aimed purely at the specialists, there is a great deal to recommend it since the volumes in the series aro well written by authori. ties in the fiolds covered. Order-Disorder Phenomena is no exception, as both authors have made significant contributions to the investigation of the subject.

The title of the book is slightly misleading, for it is essentially concorned only with a discussion of the so-called Ising model and even then mainly with the case of the two-dimensional lattices. Within this restriction the treatment is extensive and covers most recent developments. References to other work are, as seems to be an increasing tendency, patchy. The early papor by Lassettre and Howe in which the matrix mothod was proposed, independently of Kramers and Wannier, is, for example, not mentioned. Not very surprisingly, great emphasis is placed on the Pfaffian mothod developed by the authors. Unfortunately, recent devolopments and simplifications by Rumer and by Schultz, Mattis and Lieb occurred too late to be included.

The book starts with a genoral discussion of phase transitions and a statement of the Ising problem. The authors then show how far this model is applicable to the theory of ferromagnetism, antiferromagnetism and ferrimagnetism, to the theory of binary alloys and to the discussion of lattice models of fluids. A discussion follows of the rectangular two-dimensional Ising lattice and the Pfaffian theory applied to this case. Then come a chapter on the general theory and a chapter dealing with other lattices, such as the triangular and hexagonal lattices, and also discussing correlations and spontaneous magnetization. In conclusion, other methods and a few outstanding problems are discussed and six mathematical appendixes complete the book.

The book is well written and can be recommended as an introduction to various approaches to the Ising model. D. TER HAAR

\section{Zahlenwerte und Funktionen aus Physik, Chemie,} Astronomie, Geophysik und Technik

Von Landolt-Börnstein. Sechste Auflage. Zweiter Band: Figenschaften der Materie in ihren Aggregatzuständen. 2 Teil: Gleichgewichte ausser Schmelzgleichgewichten. Bandteil c: Lösungsgleichgewichte II. Bearbeitet von J. D'Ans, D. Jänchen, E. Kaufmann und C. Kux. Herausgegeben von Klaus Schäfer und Ellen Lax. Pp. viii +731 . (Berlin, Göttingen, Heidelberg: SpringerVerlag, 1964.) Moleskin 388 D.M.

GUCH is the credit rating of Landolt-Börnstein that it $S$ is not necessary to do more than to indicate the scope of this book. It opens with a continuation, from the earlier volume, of data on solubility equilibrium of solids and liquids, limited here to organic compounds. The survey of binary systems occupies rather more than half the pages; the arrangement is not difficult to follow, but to assist thore is a very full index, based on molecular formulae. To say that this part is amplified by 321 diagrams does not give a true idea of the extent of the use to which these are put, for nearly all illustrate several systems, sometimes as many as a dozen; a few give the impression of being rather overcrowded. Information on about 300 ternary and higher systems is limited to literature references.

The remainder of the space is devoted to equilibria in systems having immiscible liquid phases. After a general survey, presented in tabular form, ternary and quaternary systems are dealt with in detail, each illustrated clearly with diagrams. The last part tabulates distribution coefficients in two phase systems; most of the solutes are organic but not all; water is one of the solvents in the majority of the systems recorded.

As is acknowledged, some information has been supplied from outside sources, and one cannot but admire the manner in which it has been collected from world-wide literature and then collated. It appears to have been overlooked that $N N$-diphenylacetamide and $N$-acetyldiphenylamine are identical; however, the arrangement brings the two entries next to one another on p. 359, so confusion is minimized. $\quad$ B. A. Ellis

\section{Transactions of the Tenth National Vacuum} Symposium of the American Vacuum Society

October 16, 17, 18, Boston, Massachusetts, U.S.A. Edited by George H. Bancroft. Pp. xxi +510. (New York: The Macmillan Company; London: Collier-Macmillan, 1963.) 23 dollars; $172 s$.

$7 \mathrm{HE}$ extent of the enormous surge forward in vacuum technology and its applications in the United States during the past decade can be well appreciated by an examination of this handsomely produced volume containing 93 papers presented to 1,600 delegates at the tenth National Vacuum Symposium. The scale of activity is much greater than in Britain, and it is particularly significant that considerablo research is in progress in American universities, whereas in British colleges work on vacuum, especially in its engineering aspects, is comparatively slight. 